\title{
Developing a Top 25 Program in the Behavioral and Social Sciences
}

David Geary, Curator's Professor; Thomas Jefferson Professor, Dept. of Psychological Sciences, University of Missouri

$\mathrm{M}$ ore than ever, public research universities are constrained in how much they can invest in program development in the social and behavioral sciences, as well as many if not all other disciplines. Without such investment, however, there is an inexorable decline in facility quality, including their ability to stay at the forefront of their disciplines and their ability to compete for federal research funds. In the face of diminishing State support and federal research funding opportunities, the ability to maintain and enhance these departments will increasingly depend on creative and sometimes risky strategies.

I describe policies that are in place at the University of Missouri and how I used these as the chair of the Department of Psychological Sciences (20022005) to facilitate changes that have better positioned the department to maintain and enhance its scientific reputation and federal funding.

There are two critical and central policies that allowed us to work toward "self enhancement" without the need for additional general operating funds. The first is the College of Arts and Science policy of allowing departments to keep general operating salary funds that are covered with federal or other grants and the second is the Office of Research Policy to return $25 \%$ of facilities and administration funds to departments. When I became chair, the departmental policy was to split these funds with the investigators 50/50. Our course load at that time was four courses per academic year, and investigators could buy out of one or all of these courses at $25 \%$ of their base salary for each course. Investigators used these funds to enhance their research productivity by supporting graduate students, research assistants, buying equipment, or covering their summer salary and the department used the funds to hire full time non-regular teaching faculty and to enhance start-up packages when recruiting new faculty, among other things. These policies create strong incentives for individual investigators to secure external funding and for departmental administrators to encourage grantsmanship.

In 2002, the contributions of the Department of Psychological Sciences to the University of Missouri were evaluated in terms of the size and effectiveness of the undergraduate and graduate programs; the scientific productivity and national reputation of the faculty members; the fiscal costs and benefits of operating the department; and, the potential for improvement in national reputation. Our goal was to determine changes 
that needed to be made to become a nationally recognized top 25 department.

From 1997 to 2001, inclusive, the number of undergraduate majors had increased by $53 \%$ and faculty members had increased the number of undergraduate credit hours taught by $15 \%$. The quality of this teaching was and remains high, as indicated by a mean Teacher Effectiveness Questionnaire (TEQ) rating of about 4.1 [on a 1.0 (low) to 5.0 (high) scale]. In the 1995 National Research Council (NRC) review of graduate programs, the Department of Psychological Sciences had the highest ratings in the University of Missouri system for faculty quality and program effectiveness. The NRC review covered $185 \mathrm{PhD}$ granting programs in psychology (there are $>800$ psychology departments nationwide), and the department ranked $67^{\text {th }}$ in terms of faculty quality, and $59^{\text {th }}$ for program effectiveness. These are certainly respectable ratings, but not anywhere near the top 25 . We attracted good students (and now attract even better ones); of the 77 graduate students at that time, eighty percent had mean Graduate Record Examination scores that exceeded the university average. The department conferred about nine PhDs per year (and still does) who, in turn, competed very successfully for academic and clinical positions nationwide.

In terms of fiscal considerations and based on a University of Missouri system review of departments, operating costs for the department declined 13.6\% between 1997 and 2001, inclusive, due in part to an increase in benefits paid through external grants. The estimated tuition generated by faculty members' teaching exceeded total departmental operating costs by roughly $\$ 500,000 /$ year. In addition, the department generated roughly $\$ 500,000 /$ year in facility and administration costs for the university. In all, the Department of Psychological Sciences contributed strongly to the undergraduate and graduate programs of the university and at the same time generated income.

To move the department closer to the ultimate goal of becoming a top 25 department, we determined that an evaluation and review of the teaching and grant release policies of the top 25 departments (based on 1995 NRC ratings) was necessary. I surveyed the chairs of these departments and determined that for top public research universities, the teaching load for psychology faculty members was three courses/year, with a grant release option of two courses; the teaching load for private universities was about two/year, but with less opportunity to obtain grant-based releases from teaching. We determined that our departmental policy of four courses each academic year placed us at a disadvantage relative to these departments, both in terms of the time available to faculty members for research-related activities and in terms of the recruitment and retention of the best scientists.

During the same five-year span (1997-2001), an increase in grant-related activities created additional demands on the associated support staff and the multiple and complex grants that had been awarded to several faculty members created additional grant-administration burdens. In other words, the department's external funding had reached a 
level that would have been difficult to maintain much less increase without additional support staff.

To address these issues of teaching/research load policy and the added demands of increases in external funding - in light of the goal to further increase this funding and ultimately scientific productivity - the department proposed the following:

1. The institution of a "Research Intensive Track." As part of yearly evaluations, all faculty members are rated for their contributions to teaching, research, and service. Faculty who meet expectations for research contributions will be eligible for this track for the following academic year. The result for these faculty members will be a change in responsibilities from $40 \%$ teaching, $40 \%$ research, and $20 \%$ service, to $30 \%$ teaching (three courses each academic year), 50\% research, and $20 \%$ service. These faculty members will thereby have a teaching/research load that is consistent with that of faculty members in top 25 public research universities.

An analysis of the impact of this policy yielded an estimated loss of six courses. To address this loss, the department proposed to use cost-savings funds to hire one additional full time (seven courses/year) non-regular faculty member to serve as an undergraduate instructor. The faculty members agreed to pay a higher cost (33\% of base salary) for each course buy-out and to accept between 25\% and 50\% (depending on how many courses are bought out) instead of $50 \%$ of this buy-out, allowing the department to keep more of it. The individual (and other full-time instruc- tors) was hired (and remains with us), is paid a competitive salary and given a multi-year, renewable contract.

The proposed policy change became effective during the 2004-05 academic year. At that time we had 35 regular faculty members, 933 majors, taught about 27,000 credit hours each academic year, and as noted had mean TEQ ratings of 4.1 on a one to five scale. We currently have 34 regular faculty members, 1200 majors, teach 31,000 credit hours a year and the most recent mean TEQ ratings were 4.3 on the one to five scale. We were able to reduce overall teaching load and accommodate more undergraduate students by creating new midsized ( 100 students) courses at the sophomore and junior levels, while maintaining senior level courses at about 25 students, and requiring all faculty to teach at the undergraduate level; the only exceptions are for faculty who cover $100 \%$ of their salary from grants. The change in teaching policy has not come at a cost to undergraduate education.

2. Add a grant-writer to the staff. This individual will support grant preparation activities of the faculty and the pre-award activities of the current staff. These additional support activities will enhance the department's ability to manage our current external grants and substantively facilitate the ability to apply for and thus compete for additional external funds. The department will use facilities and administration funds that are returned to the department to support the salary of this individual. We were able to make this hire in the 200304 academic year and she remains with the department. 


\begin{tabular}{|l|l|l|l|l|l|l|}
\hline $\mathbf{2 0 0 5}$ & $\mathbf{2 0 0 6}$ & $\mathbf{2 0 0 7}$ & $\mathbf{2 0 0 8}$ & $\mathbf{2 0 0 9}$ & $\mathbf{2 0 1 0}$ & $\mathbf{2 0 1 1 *}$ \\
\hline 32 & 39 & 37 & 44 & 45 & 51 & 50 \\
\hline
\end{tabular}

Figure 1: External Grant Submissions

\begin{tabular}{|l|l|l|l|l|l|l|l|}
\hline 2005 & 2006 & $\mathbf{2 0 0 7}$ & $\mathbf{2 0 0 8}$ & & $\mathbf{2 0 0 9}$ & $\mathbf{2 0 1 0}$ & $\mathbf{2 0 1 1}$ \\
\hline$\$ 1.6$ & 2.3 & & 2.7 & 3.5 & 1.7 & 2.7 & 2.7 \\
\hline
\end{tabular}

Figure 2: External Annual Grant Dollars

Figure 1 shows the trend for external grant submissions from 2005 to 2011 (the latter is an estimate based on submissions through June 30, 2011), inclusive. There is clearly an upward trend in the number of grants faculty submit each year - making the process less burdensome on the faculty appears to result in more applications for external grants. The funding situation, of course, fluctuates especially with overall national funding for the National Institutes of Health and the National Science Foundation, the two primary sources of funding for Department of Psychological Sciences faculty. Figure 2 shows annual grant dollars from external grants during this same time period. The value for 2011 is an estimate based on funds from January 1, 2011 to June 30, 2011 and does not include two new hires that will be transferring grants to the Department. In any case, despite a difficult funding climate the Department was maintained and even increased it external funding.

The 2010 NRC ranking provided an opportunity to assess whether we have made progress toward achieving our top
25 goal. It is difficult to directly compare the 1995 and 2010 rankings, because the former provided a single rank and the latter a rank range. Moreover, the number of programs evaluated in psychology increased from about 180 to about 230. Nonetheless, using the lower value of the ranges, the Department of Psychological Sciences was ranked 41 on reputation and 29 in faculty productivity. As a comparison, the Psychology Department at the University of Texas-Austin (highest in Big 12) was 26 on reputation and 27 in faculty productivity. We seem to have gained some ground.

Before completing my term as chair, we proposed development of a state-ofthe-art Brain Imaging Center (BIC): Brain imaging research is becoming an integral component in many disciplines in the social and behavioral sciences. The Provost for Research, Dean of the College of Arts and Science, and other administrators were supportive of this initiative and took a gamble. Using facility and administration savings, the university loaned the Department $\sim$ \$3.8 million to build the center. The Department 
agreed to contribute a portion of its facilities and administration returns to repayment, along with BIC income. The Department also agreed to prioritize new hires doing brain imaging research (we have since hired three such faculty). With assistance from the Dean and Chancellor, we secured a \$1.2 million private endowment and a \$1.2 million match from the University of Missouri System for the endowed Miller Family Chair of Cognitive Neuroscience to direct the BIC. We opened the center 2 years ago and recently filled this chair (hired the director of the BIC from the University of Oregon). It is too soon to know if the BIC will be a success and further enhance the research capacity and reputation of the Department of
Psychological Sciences, but the prospects seem good.

In all, the gist is that there are university policies that can increase incentives for faculty members to seek external funding and incentives for departments to change their workload and governing policies to further support these activities. With diminishing State support, limitations on how much tuition can be increased, and stiffer competition for federal research grants, developing and maintaining strong departments in the social and behavioral sciences will require some creativity and risk taking, with the Department of Psychological Sciences being one example of this at the University of Missouri. 